\title{
Detecting areal changes in tidal flats after sea dike construction using Landsat-TM images
}

\author{
Moon Seong Kang ${ }^{1}$, Sang June Im ${ }^{2, *}$, Tae Il JAng ${ }^{3}$, \\ Seung Woo Park ${ }^{3}$ and SAng Min KIM ${ }^{4}$ \\ ${ }^{1}$ Department of Biosystems Engineering, Auburn University, 200 Tom E. Corley Building, \\ Auburn, AL36849, USA. \\ ${ }^{2}$ Department of Forest Sciences/RIALS, Seoul National University, 599 Gwanangno, \\ Gwanak-gu, Seoul, 151-921, Republic of Korea. \\ ${ }^{3}$ Department of Rural Systems Engineering/RIALS, Seoul National University, 599 Gwanangno, \\ Gwanak-gu, Seoul, 151-921, Republic of Korea. \\ ${ }^{4}$ Department of Agricultural Engineering, Gyeongsang National University, 900, Gajwa-dong, \\ Jinju, Gyeongnam, 660-701, Republic of Korea. \\ *e-mail: junie@snu.ac.kr.
}

The main objective of this study was to estimate changes in the area of tidal flats that occurred after sea dike construction on the western coast of South Korea using Landsat-TM images. Applying the ISODATA method of unsupervised classification for Landsat-TM images, the tidal flats were identified, and the resulting areas were quantified for each image. The area of tidal flats from a topographic map published in one year differs significantly from that shown in another, which appears to be attributable to the tide levels at the time of aerial photography. During the study period, the area of tidal flats, as estimated from Landsat-TM images, increased by $4.57 \mathrm{~km}^{2}$ per year in the study areas. The tidal flats in the inner sea of Chunsu Harbor area increased by $200 \mathrm{~m}^{2}$ per zone, while the accumulation for a number of inner sea areas within Asan Harbor area occurred at over $50 \mathrm{~m}^{2}$ per zone. The results of this research may serve as the basis of an environmentallyfriendly development plan for tidal flats.

\section{Introduction}

Tidal flats, also referred to as inter-tidal zones, are the areas located between the high and low water levels of shorelines. The inter-tidal zone is a shoreline landform that results from the deposition of suspended sediments by tidal movement (Odum 1989; Jo and Jo 1999; Kim et al 2003; Won and Kim 2003; Lee and Kim 2004).

Reclaimed land is a valuable land resource for land-poor regions as it allows for the creation of new agricultural and urban areas (Wagle and Hashimi 1990). In the United States, the conversion of tidal wetlands to agricultural lands dates back to colonial times (Philipp 1995; Weinstein et al 2000; Weinstein and Weishar 2002). Dutch magistrates under British rule, for example, had already completed dike and sluice construction for a roadway near New Castle, Delaware by 1675 . Moreover, there is a need to conduct periodic and systematic scientific evaluation of tidal flat areas in order to effectively manage a country's land resources.

Reclamation is the process of converting a tidal flat to developable land. Tidal flat development often involves the creation of large-scale industrial complexes and harbors, reservoir establishment and agricultural land development. Sea-dikes are structures designed to restrict the ebb and flow of the tides to allow for reclamation.

Keywords. Tidal flat; Landsat-TM image; ISODATA; sea dike; topographic map. 
There have been significant changes to the accumulation conditions along the west coast of Korea due to sea-dike construction resulting in land reclamation. The water depth outside the sea dikes has generally become shallower because of tidal current changes and silt and sand accumulation. As a consequence, newly formed tidal flats have developed within the tidal zones. The cause of the west coast post-sea-dike-construction outer accumulation changes and tidal flat formations are as follows:

- a diminution of the tidal current, resulted in the influx of suspended solids from the outer sea area accumulating near the sea-dike walls;

- sea-dike walls interrupting the sea wave pattern, which in turn interrupts the literal drift volume from the outer sea area and results in accumulation near the walls;

- flocculation occurring, causing suspended solids to drift from the river mouth into the sea and then quickly settle.

Recently, the importance of tidal flat preservation has become widely apparent. Previously, only the economic value of fisheries was considered during efforts to preserve tidal flats, and this value was compared with the economic value of the agricultural land that would be produced. However, recent environmental comparison research has begun to account for the non-market value of preserving tidal flats, which has triggered a great deal of discussion.

The spatial and temporal scope of changes to landforms, including tidal flats, varies widely (Steele 1995). Changes in soil and vegetation types do not occur quickly on land, but the environment within an inter-tidal zone is highly sensitive to changes in the tidal water level. Furthermore, the cumulative effect of shifting tidal patterns can create a diverse environment over many years. Until recently, leveling and sonic sounding conducted from boats was the only way to understand the changes to the seafloor occurring within inter-tidal zones.

However, such field investigative techniques suffer from several major disadvantages. Only localized research areas can be targeted, due to time limitations and transportation difficulties. Additionally, field techniques tend to be labor intensive and yield a limited spatial and temporal scope due to changes in the tidal water level. Moreover, because tidal water level changes occur over a wide area, changes in broad spatial patterns cannot be studied using only traditional observation methods. Tidal flat area can be estimated using topographic maps based on aerial photographs, but the accuracy of this method is negatively affected by changes in tidal water level. Although the topographic method appears to yield relatively accurate estimates, it is not able to produce reliable hydrographic charts for each time period in a study.

The large extent of tidal flats makes them difficult to map using conventional techniques. Satellite remote sensing, however, may be used for mapping tidal flats in a rapid and accurate manner. Orbital remote sensing may be used to effectively assess tidal flat accretion due to its repetitive and synoptic nature (Sanjeevi 1996).

Many researchers have used remote sensing images to classify tidal flats and analyze their characteristics. For example, the particle distribution and characteristics of tidal flats have been extensively researched using Landsat-TM data (Bartholdy and Folving 1986; Jo and Jo 1999; Jeong 2002; Ryu et al 2002, 2004; Lee and Kim 2004). Moreover, the morphology, areal change, and waterline of tidal flats have been studied by using satellite images (Sanjeevi 1996; David and Davenport 1996; Chen and Rau 1998; Kang et al 2001; Ryu et al 2002; Kim et al 2003). Studies related to inter-tidal DEM generation (Ryu et al 2000; Won and Kim 2003) and policies that affect tidal flats (Lin 1996; Weinstein and Weishar 2002; Zhao et al 2004) have also been conducted.

The objective of this study is to estimate changes in the area of tidal flats after sea-dike construction in the study area. To this end, satellite images from different dates were examined to assess the accumulation of tidal flat area that occurred after the installation of sea dikes. Results were obtained by classifying landforms and areal changes and by demarcating and analyzing regions of change, demarcating regions into zones, and analyzing the results.

\section{Tidal flats and reclamation of South Korea}

Many well-developed tidal flats exist on the west coast of South Korea as a result of numerous geomorphic processes, such as tides, surges and river basin flows. In 2002, the Korean Ministry of Maritime Affairs and Fisheries (MOMAF 2002) estimated the total area of tidal flats on the south western coast to be $2393 \mathrm{~km}^{2}$. The Korean tidal flats have an average slope of about $0.1^{\circ}$ and vary in elevation from 4 to $7 \mathrm{~m}$ (Won and Kim 2003).

A significant accumulation of tidal flats occurred outside the Asan and Sabkyo sea-dikes, which were constructed in 1970. In response, an investigation into post-sea-dike-construction tidal flat formation was initiated. According to Park (1988), the tidal flat depth inside Asan Harbor increased at a rate of $12 \mathrm{~cm}$ annually. In 1992, the Korean Agricultural 
Table 1. Characteristics of major sea dikes located in the project areas (RIALS 2001).

\begin{tabular}{|c|c|c|c|c|c|c|c|c|c|}
\hline \multirow[b]{2}{*}{ Name } & \multicolumn{5}{|c|}{ ADCA } & \multicolumn{3}{|c|}{ CNCA } & \multirow{2}{*}{$\frac{\text { SWCA }}{\text { Siwha }}$} \\
\hline & Asan & Sabgyo & Namyang & Habaragi & Daeho & Seosan A & Seosan B & Busa & \\
\hline Sea dike closing (year) & 1973 & 1978 & 1972 & 1976 & 1983 & 1985 & 1983 & 1989 & 1994 \\
\hline Elapsed time (year) & 30 & 23 & 31 & 27 & 20 & 18 & 20 & 14 & 9 \\
\hline Length of dike (m) & 2564 & 3360 & 2060 & 1696 & 4700 & 6458 & 1228 & 3470 & 12,676 \\
\hline Reclaimed area $\left(\mathrm{km}^{2}\right)$ & 35.00 & 28.30 & 36.50 & 7.45 & 74.68 & 96.26 & 57.83 & 12.21 & 173.00 \\
\hline
\end{tabular}

and Rural Infrastructure Corporation (KARICO 1992) conducted a seafloor topographical survey of the areas just outside the sea-dikes of the 12 reclaimed land development project areas on the south western coast of South Korea. Ten of the study areas, for a total area of $30.5 \mathrm{~km}^{2}$, showed an annual increase in tidal flat depth of $4.3 \mathrm{~cm}$. Moreover, KARICO (1992) confirmed that the licensed fisheries that had disappeared due to the initial construction of the sea-dikes had revived and were flourishing because of the post-sea-dike tidal flat formation.

Since the water pollution of Siwha Lake, which was made by reclamation, was raised as a social issue in 1996, the Korean government has been struggling for harmonization between development and conservation in developing tidal flats. A good example of this endeavor of the Korean government is shown in the Seamangeum Project that intends to build a sea dike from Gunsan City in Jeollabuk-do Province to Buan-gun County in the same province to secure new land of 28,300 ha and water resource in the inside. Since commencement in 1991, $85 \%$ of the sea-dike construction was completed as of 2007. In order to establish environmental preservation plan of this project, multi-dimensional researches and discussions were made jointly by the academic circle, governmentrelated agencies and non-government organizations (NGOs) for 2 years between 1999 and 2001. Government policy to continuously perform the project in an environmental-friendly manner was decided. Currently, the sea-dike construction is being conducted while the water quality control plan is being actively promoted. Researches by the academic circle and research institutes as well as joint inspection and evaluation by government and private sectors for the progress of environmental preservation plan are also being made.

The Korean government is trying to do its best in implementing global environmental-friendly reclamation by integrating experts' intelligence and wisdom. In addition, the Korean government is going to thoroughly enforce water quality control plan and supplement sea dikes and the surroundings with space for tourism and ecology. Besides, concerning reclamation land, the Korean government plans to establish future-oriented application plan useful for local development and national profit through research service contract with experts and integration of opinions from each field.

\section{Methodology}

\subsection{Study areas}

This research analyzed the general area of tidal flat formation occurring outside the sea dike walls after their construction. Three areas on the west coast of South Korea were used as study areas: the Siwha coastal area (SWCA), Asan Harbor to Daeho coastal area (ADCA), and Chunsu Harbor to Nampo coastal area (CNCA). The ADCA includes the sub-areas of the Daeho dike, the Habaragi dike, the Sabkyo dike, the Asan dike and the Namyang dike. The width of Asan Harbor is approximately $2 \mathrm{~km}$ and the coastal area is approximately $100 \mathrm{~km}^{2}$. The Busa dike, and Seosan A and $\mathrm{B}$, make up the CNCA. The entrance to Chunsu Harbor is approximately $5 \mathrm{~km}$ wide. Construction of the Siwha dike in the SWCA began in 1987 and was completed in 1994. The contributing area of the Siwha dike's basin is $476.50 \mathrm{~km}^{2}$, and the dike is equipped with $8 \mathrm{~m} \times 6.5 \mathrm{~m}$ sluice gates that currently remain open and do not control the freshwater lake. Table 1 and figure 1 show the characteristics of their major sea dikes and the location of the study.

\subsection{GIS and image data used}

The Rural Geographical Information System (RGIS) operated by KARICO is used for the purpose of extracting ground control points (GCPs) and improving the accuracy of land cover classifications. GCPs are specific pixels in an image for which the output map coordinates are known (ERDAS 1991; Lillesand and Kiefer 1994). GCPs consist of a pair of X, Y coordinates. The RGIS data makes use of the RGIS standard code and consists of a 1/50,000 topographical map, a 1/25,000 agricultural land use map and a 1/50,000 river system map. 


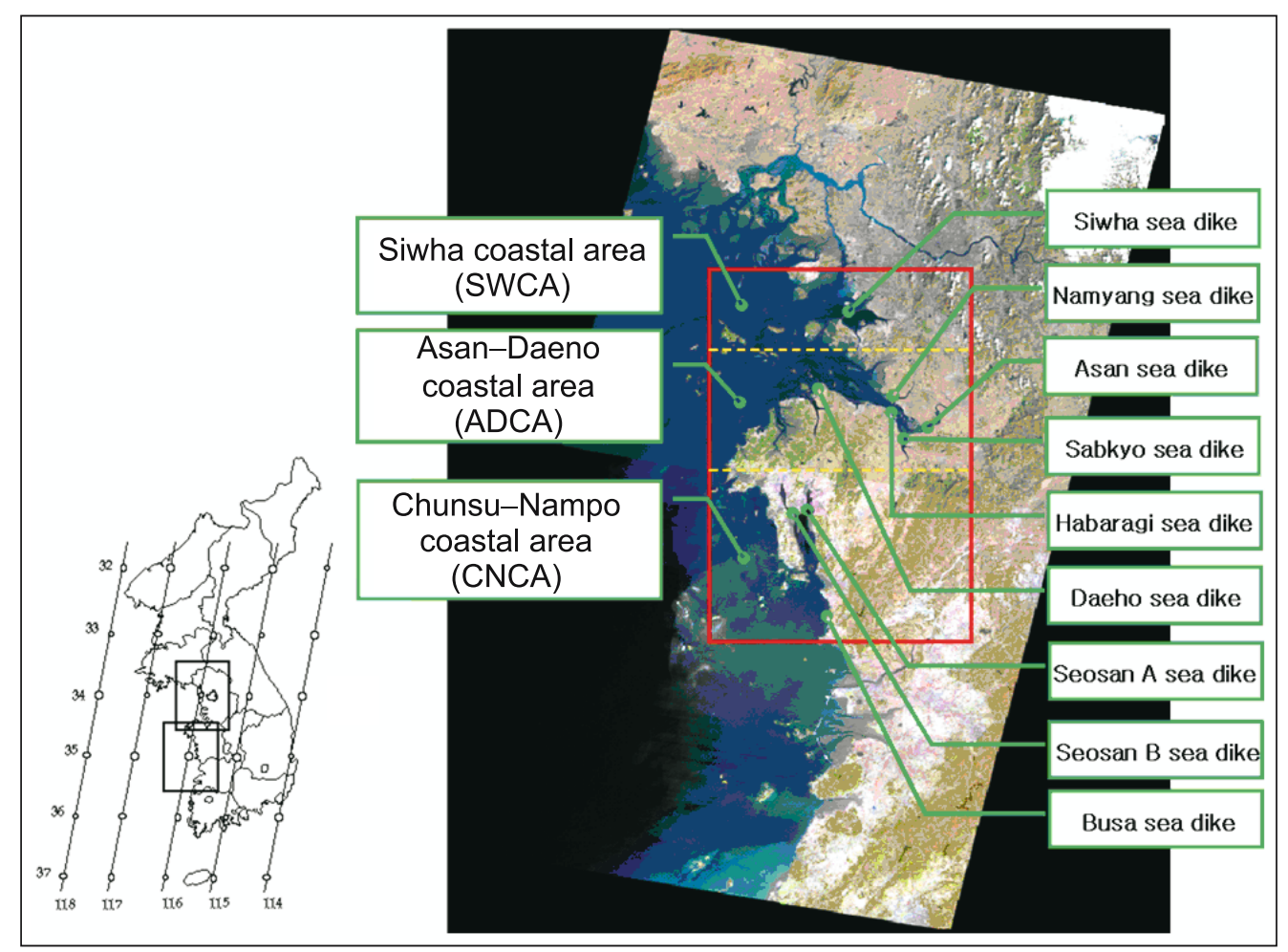

Figure 1. Location of the project areas.

Satellite imagery was obtained through RESTEC (Remote Sensing Technology Center of Japan). The imagery was recorded by the Landsat5 TM sensor from 1984 to 2000 on Path 116, Rows 34 and 35 (table 2). The imagery was georegistered using the Transverse Mercator coordinate system. The images were selected by considering the time that they were taken, their inclusion of clouds and their overall quality. The images assessed are very complicated due to their inclusion of spatially and categorically diverse land cover types, as well as for their inclusion of cloud cover. For example, the tidal water level was $69.75 \mathrm{~cm}$ at the time image A_000320 was taken and the image clearly shows the shape of the tidal flat. However, for image A_901019, which was taken when the tidal water level was $66.15 \mathrm{~cm}$, land cover was difficult to classify due to cloud cover.

Despite there being cloud interference in image A_901019, it was selected along with image A_000320. The increase in tidal flat area was estimated by conducting a land cover classification on image A_901019 and masking image A_000320 in order to eliminate the effects of the cloud cover. To observe changes in the tidal flat area with respect to changes in the tidal water level, image A_900410 was selected for comparison with image A_901019.

A mosaic of the study area was created using ERDAS with images taken from Path 116/Row 34 and Path 116/Row 35 on March 20th, 2000, October 19th, 1990, and April 10th, 1990 (figure 2). Resampling was carried out for the entire study area on the west coast, followed by another round of resampling for each study area of the ADCA, the CNCA and the SWCA. Changes in tidal flat area were then examined.

Unsupervised classifiers do not utilize training data as the basis for classification. Rather, the classes that result from unsupervised classification are spectral classes. The analyst must compare the classified data with some form of reference data. Thus, we determined a set of spectrally separable classes and then defined their information utility using the RGIS data.

For the plane geometry revision, a coordinate conversion equation was extracted by using the GCPs on each multi-temporal image coordinate and topographic map and applying the method of least squares. The number of GCPs for most images was 34; however, image C_940912 had only 17 points due to those GCPs obscured by clouds not being included (table 2 ). The coordinate conversion results showed that the value of the root mean square error (RMSE) for images A_940912 and $A_{-} 861211$ was the lowest, at 0.096 pixels, and that the value of the RMSE for image C_9400410 was the greatest, at 0.1849 pixels. The mean RMSE was 0.1601 pixels (table 2 ). 
Table 2. Characteristics of TM image data and results of transformation.

\begin{tabular}{|c|c|c|c|c|c|}
\hline \multirow[b]{2}{*}{ Code } & \multicolumn{2}{|c|}{ TM images } & \multirow[b]{2}{*}{ Reference } & \multirow[b]{2}{*}{ No. of $\mathrm{GCP}^{(1)}$} & \multirow[b]{2}{*}{$\begin{array}{c}\mathrm{RMSE}^{(2)} \\
\text { (pixel) }\end{array}$} \\
\hline & $\begin{array}{c}\text { Time } \\
\text { (h:min) }\end{array}$ & $\begin{array}{l}\text { Tidal height } \\
\qquad(\mathrm{cm})\end{array}$ & & & \\
\hline A_ 000320 & $10: 45$ & 69.75 & $\mathrm{PT}^{(3)}$ & 34 & 0.1559 \\
\hline A_990521 & $10: 49$ & 712.53 & PT & 34 & 0.1584 \\
\hline A_981110 & $10: 50$ & 566.85 & $\mathrm{IC}^{(4)}$ & 34 & 0.1584 \\
\hline A_970616 & $10: 40$ & 539.08 & IC & 34 & 0.1772 \\
\hline A_960901 & $10: 27$ & 450.50 & $\mathrm{IC}$ & 34 & 0.1553 \\
\hline A_940912 & $10: 27$ & 665.50 & $\mathrm{IC}$ & 34 & 0.0960 \\
\hline A_920922 & $10: 33$ & 534 & IC & 34 & 0.1749 \\
\hline A_901019 & $10: 30$ & 66.15 & $\mathrm{IC}$ & 28 & 0.1694 \\
\hline A_900410 & $10: 31$ & 160.93 & $\mathrm{IC}$ & 34 & 0.1578 \\
\hline A_ 880927 & $10: 41$ & 106.20 & $\mathrm{IC}$ & 33 & 0.1616 \\
\hline A_ 861211 & $10: 29$ & 444.07 & $\mathrm{IC}$ & 33 & 0.0960 \\
\hline A_ 850514 & $10: 41$ & 522.87 & $\mathrm{IC}$ & 34 & 0.1608 \\
\hline A_ 840730 & $10: 40$ & 322.28 & $\mathrm{IC}$ & 28 & 0.1605 \\
\hline C_000320 & $10: 45$ & 63 & $B Y^{(5)}$ & 27 & 0.1692 \\
\hline C_990521 & $10: 49$ & 462.9 & BY & 27 & 0.1692 \\
\hline C_981110 & $10: 50$ & 326.67 & BY & 27 & 0.1572 \\
\hline C_960901 & $10: 28$ & 191 & BY & 27 & 0.1779 \\
\hline C_940912 & $10: 28$ & 406.4 & BY & 17 & 0.1727 \\
\hline C_920922 & $10: 33$ & 490.5 & BY & 27 & 0.1789 \\
\hline C_901019 & $10: 30$ & 298 & BY & 25 & 0.1697 \\
\hline C_900410 & $10: 31$ & 302.73 & BY & 25 & 0.1849 \\
\hline C_880927 & $10: 42$ & 199.6 & BY & 25 & 0.1569 \\
\hline C_861211 & $10: 30$ & 561.5 & BY & 27 & 0.1627 \\
\hline C_840730 & $10: 40$ & 162.67 & $\mathrm{KS}^{(6)}$ & 25 & 0.1603 \\
\hline
\end{tabular}

(1) denotes ground control point.

(2) denotes root mean square error.

${ }^{(3)},{ }^{(4)}$, and ${ }^{(5)}$ denote Pyongtaek, Incheon, and Boryeong, respectively.
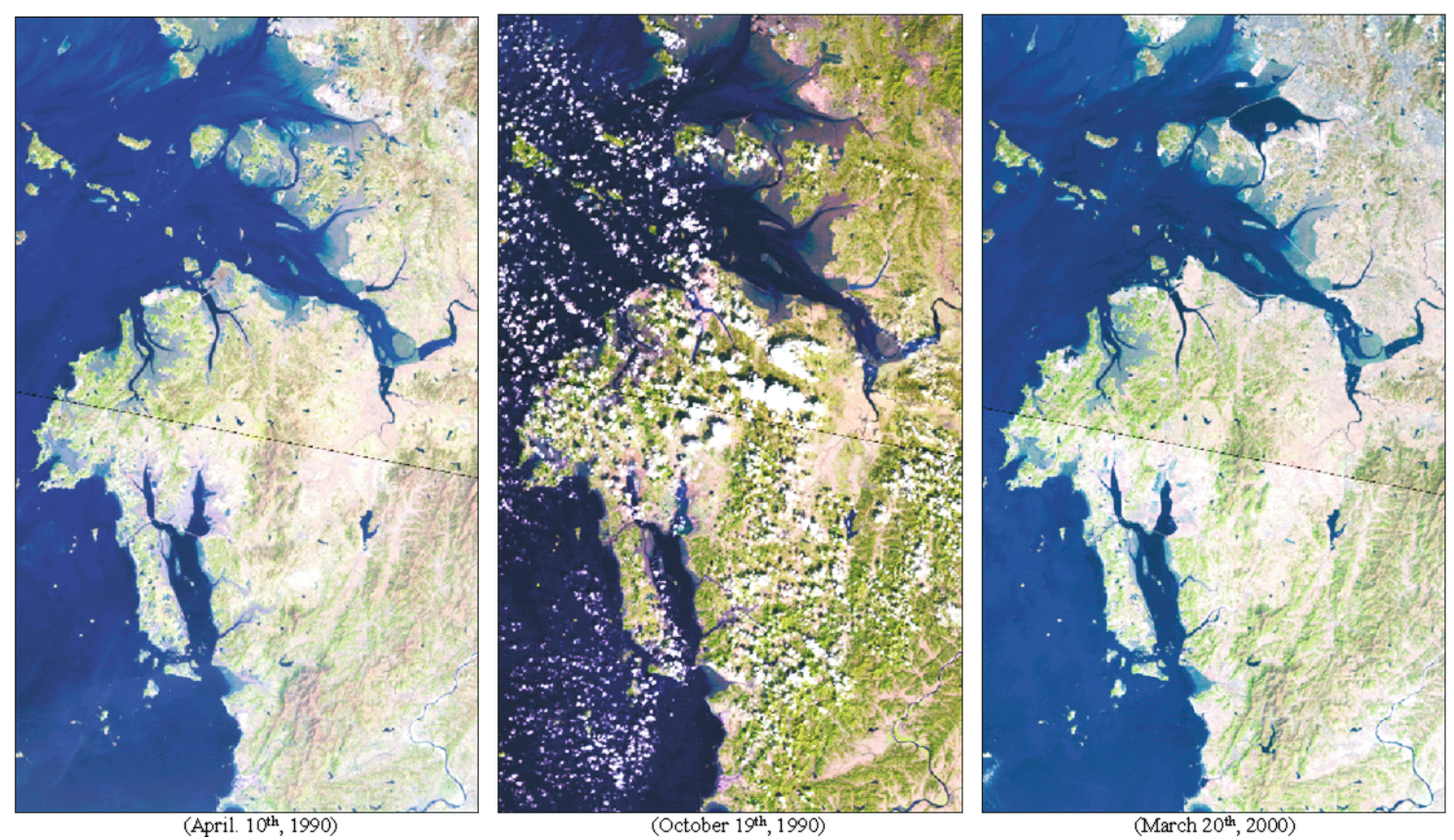

Figure 2. Images mosaicked and resampled. 
Table 3. Characteristics of topographical maps and hydrographic charts (Kang et al 2001).

\begin{tabular}{|c|c|c|c|c|c|c|c|c|}
\hline \multirow[b]{2}{*}{ Section } & \multicolumn{4}{|c|}{ Topographical maps } & \multicolumn{4}{|c|}{ Hydrographic charts } \\
\hline & Map no. & Year & Code name & Scale & Map no. & Year & Code name & Scale \\
\hline $\begin{array}{l}\text { SWCA } \\
\text { ADCA }\end{array}$ & NJ52-9 & $\begin{array}{l}1987 \\
1977 \\
1974 \\
1963 \\
1914\end{array}$ & $\begin{array}{l}\text { TA_1 } 1987 \\
\text { TA_- } 1977 \\
\text { TA_ } 1974 \\
\text { TA_ } 1963 \\
\text { TA_ } 1914\end{array}$ & $\begin{array}{l}1: 50,000 \\
1: 250,000\end{array}$ & No. 307 & $\begin{array}{l}1998 \\
1996 \\
1993 \\
1987 \\
1983\end{array}$ & $\begin{array}{l}\mathrm{SA}_{-} 1998 \\
\mathrm{SA}_{-} 1996 \\
\mathrm{SA}_{-} 1993 \\
\mathrm{SA}_{-} 1987 \\
\mathrm{SA}_{-} 1983\end{array}$ & $1: 50,000$ \\
\hline $\mathrm{CNCA}$ & NJ52-13 & $\begin{array}{l}1996 \\
1991 \\
1977 \\
1964\end{array}$ & $\begin{array}{l}\text { TC_1996 } \\
\text { TC_1991 } \\
\text { TC_1977 } \\
\text { TC_1964 }\end{array}$ & $1: 50,000$ & No. 322 & $\begin{array}{l}1997 \\
1989 \\
1984 \\
1977 \\
1974 \\
1960\end{array}$ & $\begin{array}{l}\mathrm{SC}_{-} 1997 \\
\mathrm{SC}_{-} 1989 \\
\mathrm{SC}_{-} 1984 \\
\mathrm{SC}_{-} 1977 \\
\mathrm{SC}_{-} 1974 \\
\mathrm{SC}_{-} 1960\end{array}$ & $1: 75,000$ \\
\hline
\end{tabular}

\subsection{Topographical maps and hydrographic charts}

This research did not estimate the tidal flat area through direct use of the Landsat-TM image analysis and by directly examining the tidal levels. In order to supplement the above problem, all the existing topographical maps, hydrographic charts and Landsat-TM images of the target area were obtained and a thorough analysis was conducted. Research such as this requires gathering a great deal of data in order to analyze the changes in a large area's land coverage changes over a lengthy period.

However, data drawn from topographic maps and hydrographic charts suffer from a serious weakness. Because a topographical map is a result of aerial photography and does not differ significantly from an aerial photograph in terms of the difference between approximate lowest low water levels (approx. LLW), this approach has the limitation of not being able to objectively exhibit per-year tidal flat area changes. Topographic maps used in this study were issued by the Korean National Geographic Information Institute as shown in table 3.

Compared to a topographical chart, the hydrographic chart issued by the Maritime Ministry's National Maritime Research Institute shows special features related to seas in greater detail and more precisely (table 3 ). However, because the sea surface elevation on the hydrographic chart was recorded in spot height type, this presented limitations in representing the elevations as contours. Furthermore, the seasonal hydrographic charts had the following limitations:

- They showed an identical sea surface elevation, i.e., they suffered from limitations in clearly showing differences in the sea surface elevation; and

- the margin of error for the seasonal hydrographic charts made up of a series of small scale maps was significant vis-a-vis determination of the sea surface elevation.

Table 3 shows characteristics of all the available topographical maps and hydrographic charts in this study, respectively.

The variation of tidal flat areas from topographic maps and hydrographical maps was estimated by the following procedure:

- Registering maps by a digitizer to four tic points for a coverage representing known locations on the earth's surface and land cover such as land, tidal flat, and sea.

- Creating raster data with resolution of $1 \mathrm{~m}$ by using ArcView.

- Changing raster data to vector coverage by ArcInfo.

- Classifying the features, grouping and calculating tidal flat areas.

\subsection{Image classification}

Image analysis was completed with PC-based software including ERDAS IMAGINE, IDRISI and ArcView. In order to use multi-temporal images to observe annual changes in the long-term tidal flat area, a clustering algorithm incorporating an unsupervised classifier was selected. In addition, the Iterative Self-Organizing Data Analysis Technique (ISODATA) clustering method, a nonhierarchical clustering method that is the most widely used multi-type clustering algorithm, was applied (ERDAS 1991; Lillesand and Kiefer 1994). The ISODATA method uses a minimum spectral distance to assign a cluster for each candidate pixel. The process begins with a specified number of arbitrary cluster means or the means of existing signatures and then processes them repetitively. Processed means are shifted to the means of the clusters in the data. This algorithm is highly successful at finding spectral clusters that are inherent 
in image data. It does not matter where the initial arbitrary cluster means are located, as long as enough iteration is allowed.

As a study area may span several image files, it may be necessary to combine the images to create one large file known as a mosaic. One Landsat-TM image did not cover the study area, thus a mosaic comprising Path 116/Row 34 and Path 116/Row 35 was constructed.

The overlap function was performed to combine the images. In this study, the average method was used that the value of each pixel in the overlap area was replaced by the average values of the corresponding pixels in the overlapping images.

Several researchers recommended a maximum tolerable RMS error value of $<0.5$ pixels (Jensen 1996), but others like Rogan and Chen (2004) stated that the acceptable RMSE depends on the type of satellite images and referring topographic maps. In this study, the two mosaicked images were well matched and the digital administration boundaries were small. Therefore, the total RMS error of $<0.5$ pixels was evaluated to be satisfactory.

For the purpose of determining the pixel value of the images, resampling was carried out by applying the Nearest Neighbor method. This widely used resampling method is the best way to determine the closest pixel value of the coordinate converted image when the original image and the coordinateconverted image are juxtaposed. The resampled images included all of the target study areas on the western coast. The total exposed area of $\mathrm{X}$ $(117,000,203,400), \mathrm{Y}(292,500,447,790)$, with 2881 columns and 4933 rows, was resampled to $30 \mathrm{~m}$ by $30 \mathrm{~m}$.

Three categories of 'land', 'tidal flat' and 'sea' were made using an unsupervised classification in this research, and the tidal flat border area was then classified into 'shallowly submerged areas' and 'areas of wet mud'. At the time of making the land cover classification by utilizing the area's image, a survey using Differential Global Positioning (DGPS) was carried out in order to extract the ground control points (GCP) and enhance the unsupervised classification process.

The DGPS measurements were performed by selecting the areas of wet mud and shallowly submerged areas in each target area. The tidal flat category, at the time of the unsupervised classification, was based on the DGPS measurement results. Hence, after the selected images had been divided into 30 clusters, further categories of 'the land area' and 'the tidal flat area' were made. After the extracted border was masked, the masked data and resampled images were overlaid to classify the inside of the target area's cover types into
30 clusters. By utilizing these 30 clusters, the final sea and tidal flat categories were classified.

Because a unique characteristic of the Korean tidal flats is that they support very little vegetation, it is safe to say that its influence is not significant. Consequently, it was not considered at the time of making the land cover classifications.

\section{Results and discussion}

\subsection{Changes in the area of tidal flats}

There are significant differences in relative spectral response profiles between corresponding LandsatTM spectral bands. The spectral reflectance of landuse has a direct relationship with soil color, as well as to other parameters such as soil moisture, soil texture, organic matter, atmospheric and illumination condition (Teillet et al 2007). Figure 3 shows the spectral characteristics of each band. The results of the DN (Digital Number) value distribution were not significant trends in band 1 , band 2 , and band 3 , but other bands had obvious distinctions except band 6 . Thus, land, tidal flat and sea were potentially good classifications in the absence of surface reflectance spectra.

The analyst must compare the classified data with some form of reference data. Thus, we determined a set of spectrally separable classes and then defined their information utility using the RGIS data. Table 4 shows the classification error matrix applied to determine how well a classification has categorized a representative subset of pixels used in the training process for the unsupervised classification approach.

The accuracy of the entire map was assessed by constructing an error matrix using 445 testing plots divided among land, sea, and tidal flat. First, a random sample of pixels was located on the map and image products, and each location was interpreted on RGIS data (reference data) to ascertain the agreement between the predicted (remote sensing) class and the actual class. The results of this accuracy assessment are reported in the form of contingency tables (table 4).

The error matrix indicates an overall accuracy of more than $90 \%$ for all images. However, the tidal flat classification accuracy was around $70 \%$. As such, it was lower than other classification categories. The reason is that there is a likelihood that tidal flats close to the areas of mud would be classified as 'land area' and the shallowly submerged areas as 'sea'.

The area of the tidal flats, which were generated after dike construction, for the entire west coast study area, according to the images of April 10, 1990 , was $670.83 \mathrm{~km}^{2}$; on October 19, 1990, it 


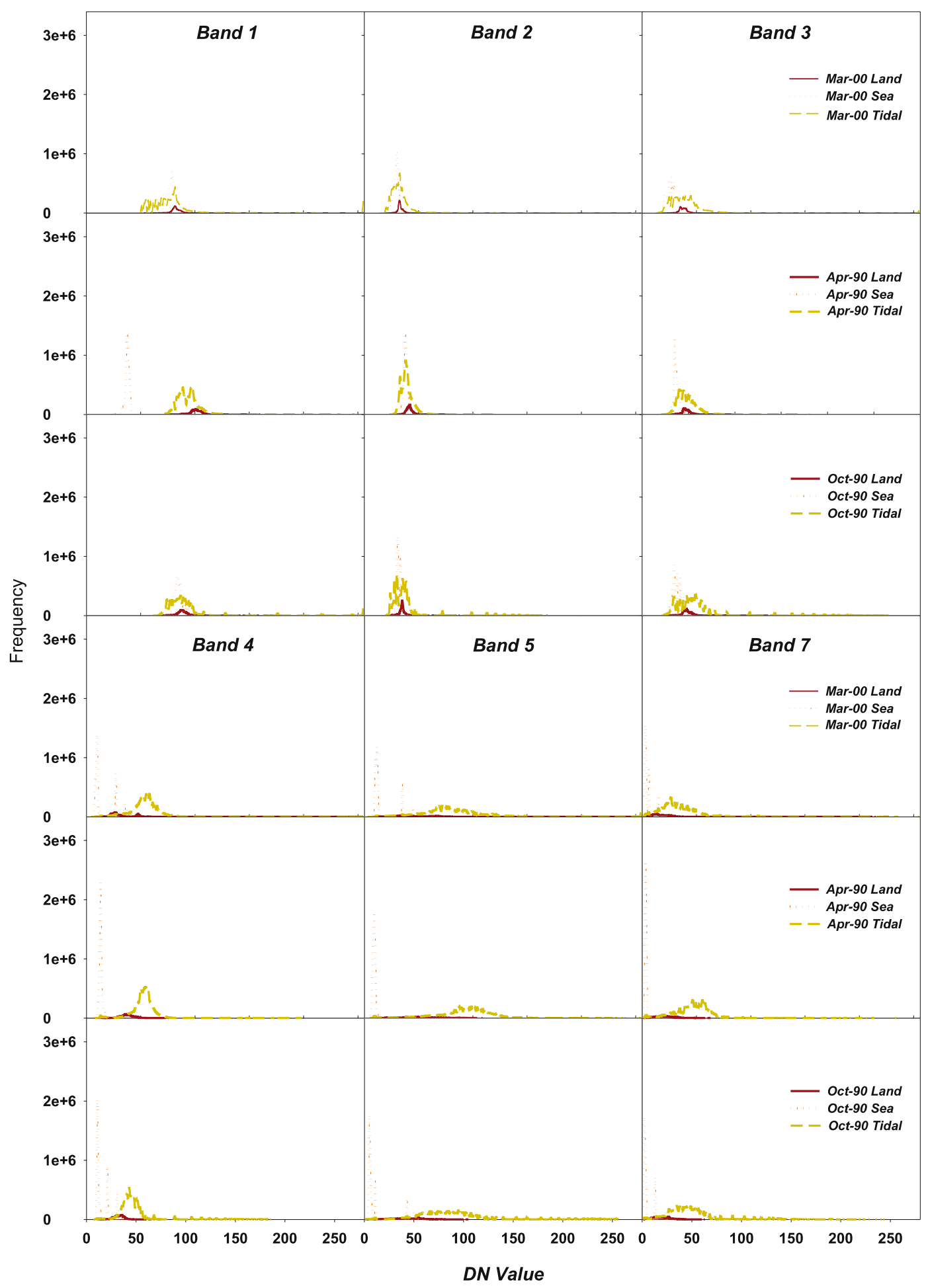

Figure 3. Spectral characteristics.

was $685.59 \mathrm{~km}^{2}$; and on March 20, 2000, it was $731.29 \mathrm{~km}^{2}$ (table 5). Thus, based on the image taken on April 10, 1990, there was an increase of approximately $60.46 \mathrm{~km}^{2}$ over the 10-year period of assessment. Calculations based on the image taken on October 19, 1990, show an increase of approximately $45.69 \mathrm{~km}^{2}$ for a similar period. These results suggest a mean annual increase in tidal flat area, after dike construction, of $6.05 \mathrm{~km}^{2} / \mathrm{yr}$ or $4.57 \mathrm{~km}^{2} / \mathrm{yr}$.

Based on this observation, when the area of a tidal flat is estimated using satellite images, the increase in area resulting from the tidal water level differential must be considered. The effort 
Table 4. Error matrix for the unsupervised classified images.

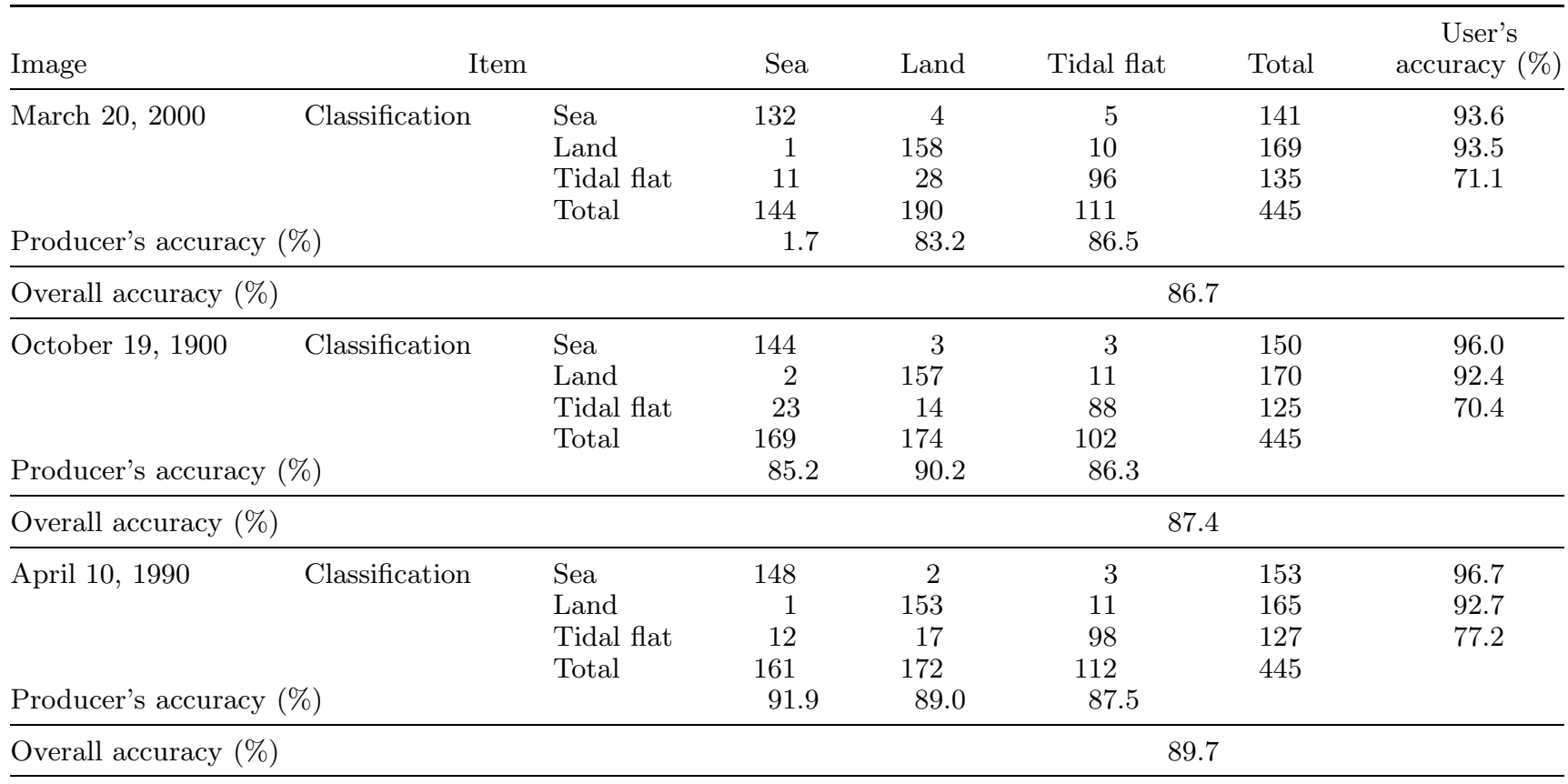

Table 5. Area changes of tidal flats for each region.

\begin{tabular}{lccc}
\hline & \multicolumn{3}{c}{ Landsat-TM $\left(\mathrm{km}^{2}\right)$} \\
\cline { 2 - 4 } Section & 1990 & 2000 & Differential \\
\hline CNCA & 259.63 & 275.30 & 15.67 \\
ADCA & 268.77 & 292.41 & 23.63 \\
SWCA & 157.18 & 163.58 & 6.40 \\
Sum & 685.58 & 731.29 & 45.70 \\
\hline
\end{tabular}

to supplement the nearly identical images of the tidal level differential was to extract the tidal flat areas from the images and analyze them separately. Thus, the nearly identical tidal level differential of $3.6 \mathrm{~cm}$ from the A_000320 image and the A_901019 image were used to estimate the tidal flat area and run the analysis. The reason for selecting these images from 1990 and using them for the comparison was to show the tidal flat area change relative to the tide level difference between two relatively close time periods. The tidal water level differential between April 10, 1990, and October 19, 1990, was $95 \mathrm{~cm}$ and the consequential tidal flat area differential was $14.76 \mathrm{~km}^{2}$. Of course, this value would change depending on the sea surface elevation during high tide and low tide, but this was considered a liable approach to suggest a relative value while facing the limitation of not being able to utilize the Landsat-TM images to extract the precise tide depth. The increase in tidal flat area for each study area appeared to be similar (figure 4), but the increase of $23.63 \mathrm{~km}^{2}$ seen in the ADCA was greatest (table 5).
4.2 Comparison of topographical maps, hydrographic charts and Landsat-TM images

The only areas for which sufficient topographical maps, hydrographic charts and Landsat-TM images were available were Asan Harbor and Chunsu Harbor. Thus, the changes of the postdike-construction tidal flat area at Asan Harbor and Chunsu Harbor were studied using topographic maps, hydrographic charts, and LandsatTM images. As mentioned earlier, the tidal flats from topographic maps published in one year differ significantly from those in another, which appears to be due to the tide levels at the time the aerial photographs, which the maps are based on, were taken (Kang et al 2001; RIALS 2001). The hydrographic charts showed that area of the tidal flats increased at rates of $0.223 \mathrm{~km}^{2} / \mathrm{yr}$ at Asan Harbor and $0.566 \mathrm{~km}^{2} / \mathrm{yr}$ at Chunsu Harbor after the construction of the dikes. Applying the ISODATA method of unsupervised classification to the Landsat-TM images, the tidal flats were identified and the resulting acreages for each image were estimated. The results showed that the tidal flats increased by $0.213 \mathrm{~km}^{2} / \mathrm{yr}$ at Asan Harbor and $0.473 \mathrm{~km}^{2} / \mathrm{yr}$ at Chunsu Harbor during the twelve years since the construction of the dikes (figure 5). The rates of annual increase calculated from the two sets of data are very close, and the differences likely result from variations in the coast lines shown in the charts and TM images (figure 5).

This analysis resulted in similar values to the value of less than $0.1 \mathrm{~km}^{2} / \mathrm{yr}$ shown by the 

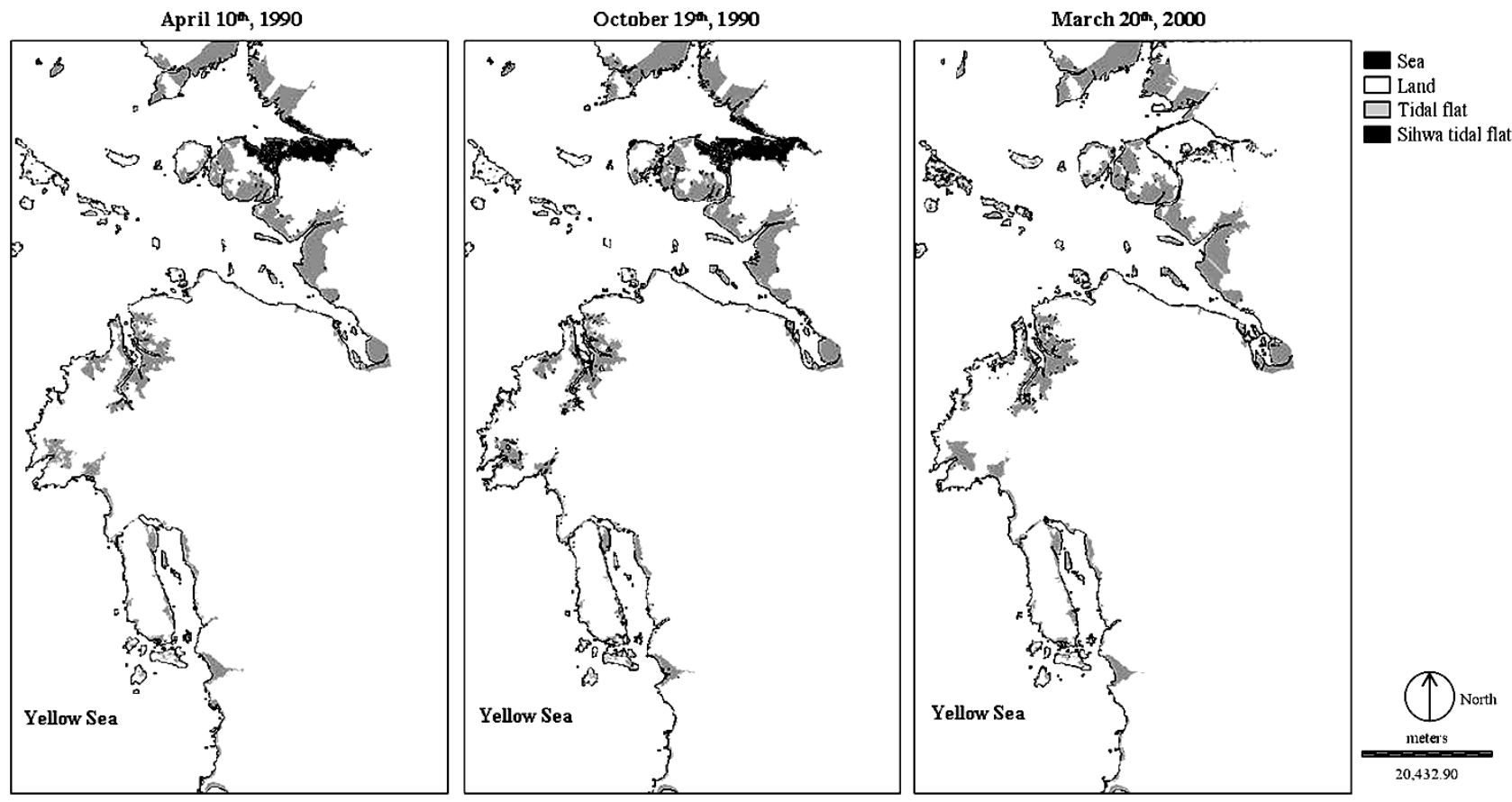

Figure 4. Yearly variations of tidal flat area estimated from TM images.

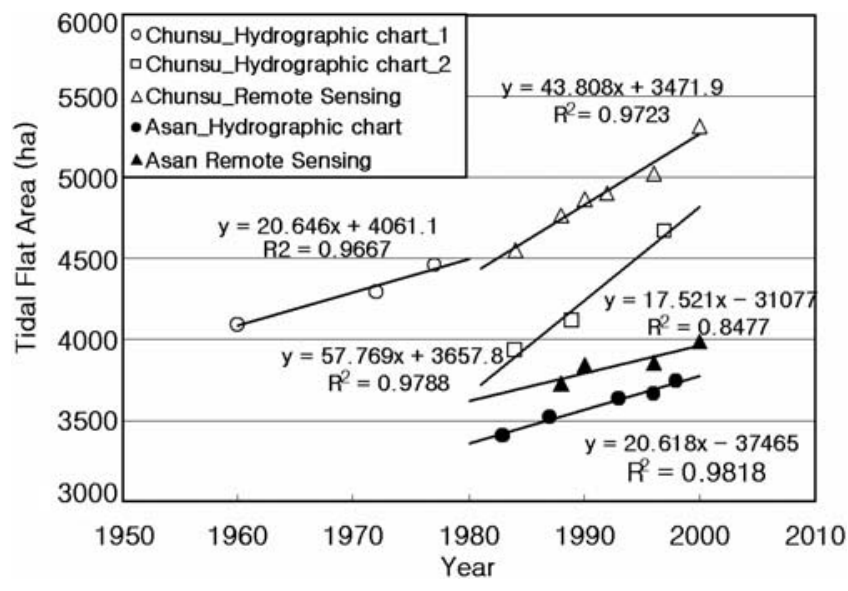

Figure 5. Variations in the tidal flat area at Asan Harbor and Chunsu Harbor.

hydrographic charts and images. Consequently, an attempt was made to deal with the small tidal level differential by applying the categories simultaneously and utilizing the categories used in making unsupervised categorizations of the images to other areas. More details on the specific comparison of topographical maps and hydrographic charts can be found in Kang et al (2001).

\subsection{Tidal flat area changes by the littoral drift changes}

The littoral drift volume change incurs changes in the accumulation condition in the breaking wave

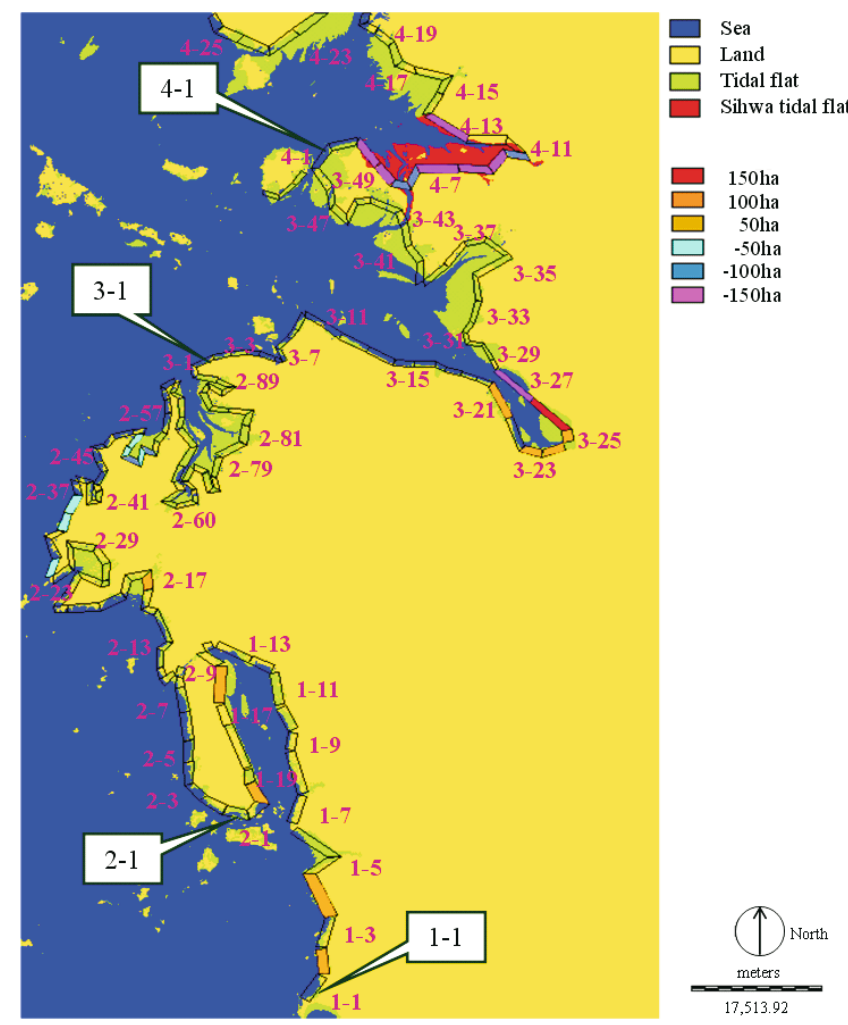

Figure 6. Area changes in the tidal flats between 1990 and 2000 for each zone.

zone and the adjacent sea areas. In the case of a significant littoral drift volume change, a new shoreline can be created or the existing shoreline can be subjected to erosion and disappear. The 


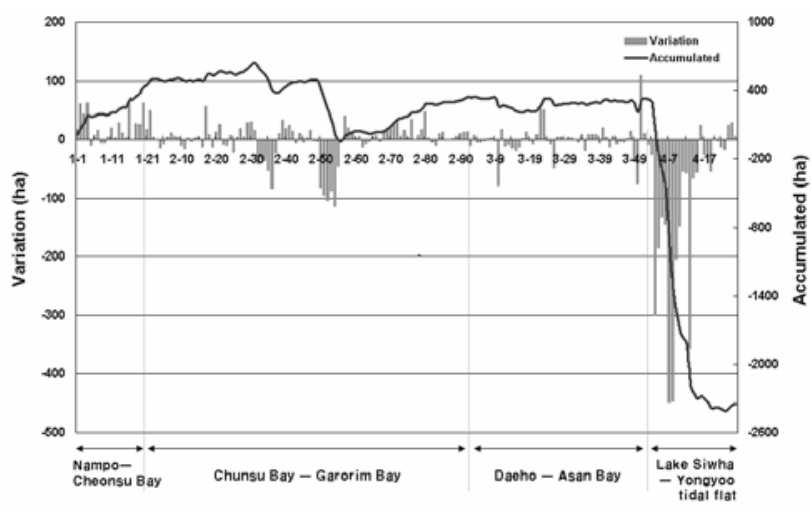

a) as a whole

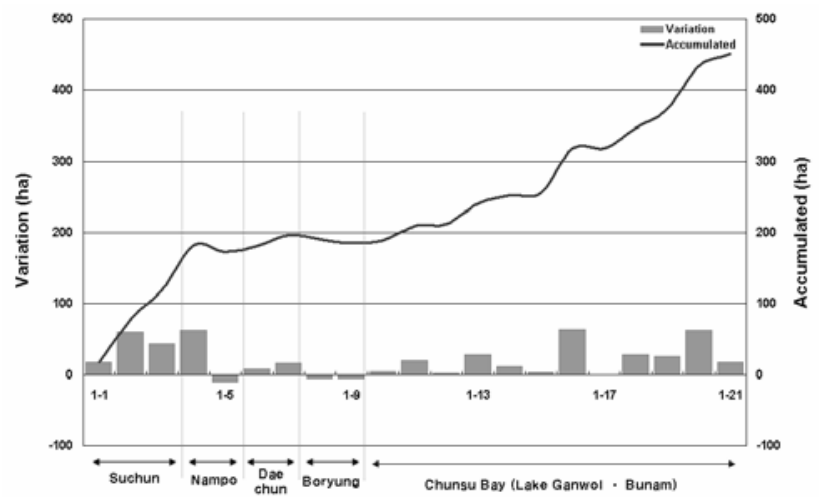

b) region I

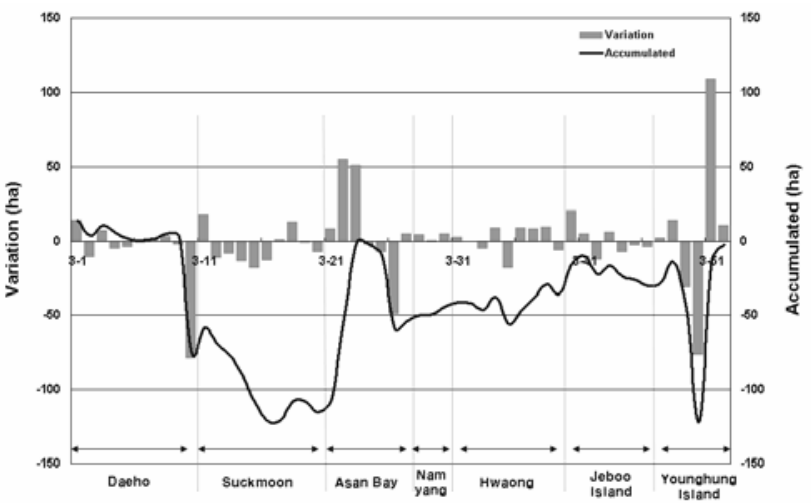

d) region III

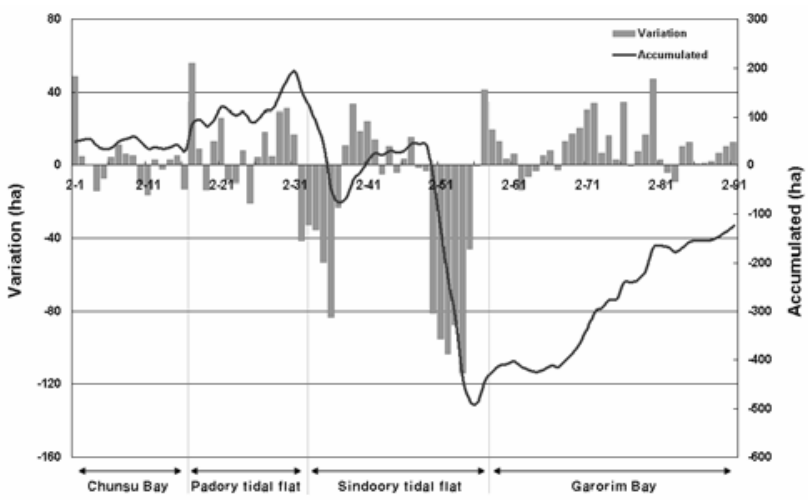

c) region II

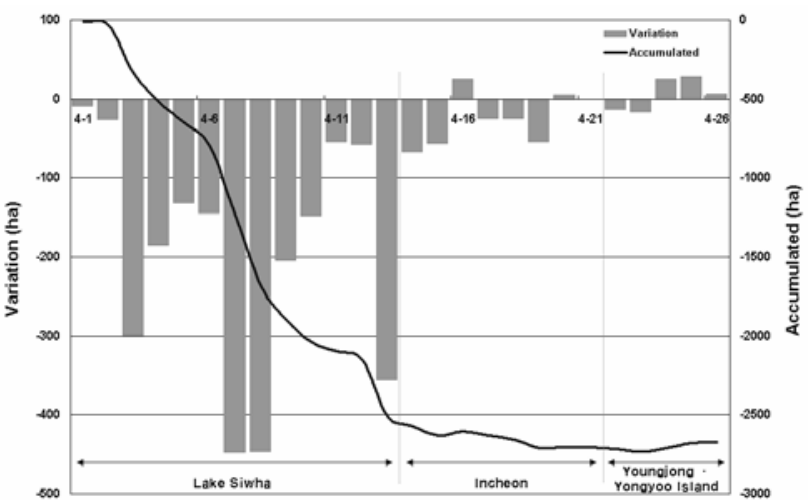

e) region IV

Figure 7. Variations in the tidal flat area for the zone: (a) as a whole, (b) region I, (c) region II, (d) region III, and (e) region IV, respectively.

changes in the littoral drift may be limited to the areas adjacent to the sea dike or breakwater and similar sea structures, but may also lead to changes tens of kilometers away.

In order to examine the post-sea-dike construction tidal flat area change incurred by the littoral drift changes, this research (i) created zones along the border of sea structures including sea dikes and land; and (ii) estimated the tidal flat area accumulation for each zone. In other words, rather than including all the created tidal flat areas within the target area by considering the littoral drift volume, only the changes within the zones determined along the border needed to be examined.

Separate zones were established along the west coast study area, and the tidal flat area increase for each section was measured by examining satellite images taken between 1990 and 2000. To compare the relative accumulation comparison between the inner sea and open sea areas, the following scheme was devised:

- the CNCA was divided into 21 zones in bloc 1 , and 91 zones in bloc 2, for a total of 112 zones; 
- the ADCA was designated as bloc 3 and was made up of 52 zones; and

- the SWCA was designated as bloc 4 and was made up of 26 zones.

Thus, cumulative changes were observed in a total of 180 zones. As for the accumulation rate of each area, findings showed that tidal flats in the inner sea of Chunsu Harbor area increased by 200 ha per zone and that the area accumulated for a number of inner sea areas within Asan Harbor was over 50 ha per zone (figure 6).

Bloc 1 within Nampo-Chunsu Harbor inner sea area had an overall increase in tidal flat area. However, from Chunsu Harbor open sea area, the tidal flat area decreased with increasing distance from Garorim Harbor. For the zones around Daeho-Asan Harbor, the overall tidal flat area increased towards the inner sea area of Asan Harbor. There was a significant overall decrease in the area of the Siwha tidal flat (figure $7(\mathrm{a})$ ). This is likely because the Siwha coastal zone was behind the Siwha Estuary Dam, and the area of the tidal flat inside the Siwha Estuary Dam was not calculated from the 2000 satellite image because there was freshwater behind the Siwha Estuary Dam.

As shown in figure 7(b) and 7(c), as with bloc 1, the tidal flat area in bloc 2, i.e., the CNCA, decreased for the Nampo section and the Boryung dike area. However, there was a significant increase in the tidal flat area for the zones in Suchun and Chunsu Harbor inland sea. The area of Chunsu Harbor open sea tidal flat increased in the Padori tidal flat and Garorim Harbor coastal zones, but showed a decrease in the Shindoori tidal flat zone.

Bloc 3 showed an overall increase in the tidal flat area for Asan Harbor coastal zone, but a relatively low increase in the open sea areas of the Sukmoon dike zone. However, there was a significant increase in tidal flat area in Asan Harbor inland sea zones, from zones 3 to 26 . There was no significant increase in tidal flat area in any of the zones within Asan Harbor inland sea. This was because the increases for Asan Harbor inland area accumulation were already included in the increases within that zone. Tidal flat area increases around the Namyang dike, the Hwayong dike and Jebu Island were due to the advancement of the open sea causing erosion and subsequent deposition in these areas. However, no increases were as significant as the increase in tidal flat area at Asan Harbor (figure $7(d)$ ).

As shown in figure 7(e), the tidal flat areas for zones within bloc 4 , the SWCA, showed a decrease from 1990 to 2000. This is because a zoning partition was formed prior to the construction of the Siwha dike and thus the zoned areas were treated as part of the inland sea area. However, the tidal flat area increased around Youngjong Island and in other areas.

\section{Conclusions}

The changes in the area of tidal flats after the construction of sea dikes on the western coast of South Korea were studied using Landsat-TM images. Applying the ISODATA method of unsupervised classification for Landsat-TM images, the tidal flats were identified, and their apparent areas were recorded. By obtaining and using the multi-temporal satellite images, the tidal flat area accumulated external to the sea dikes, after their construction, was determinable through landform classification, demarcation and analysis.

The post-dike-construction tidal flat area of the entire west coast study area, based on the images of April 10, 1990 and October 19, 1990, increased by $6.05 \mathrm{~km}^{2} / \mathrm{yr}$ and $4.57 \mathrm{~km}^{2} / \mathrm{yr}$ respectively, during the period up to March 20, 2000. The tidal water level differential between April 10, 1990 and October 19, 1990, was $95 \mathrm{~cm}$, and the consequential tidal flat area differential was $14.76 \mathrm{~km}^{2}$. Thus, when the area of a tidal flat is estimated using satellite images, the increase in tidal flat area resulting from the tidal water level differential must be considered. During the 12 years following dike construction, the areas of the tidal flats increased by $0.213 \mathrm{~km}^{2} / \mathrm{yr}$ at Asan Harbor and $0.473 \mathrm{~km}^{2} / \mathrm{yr}$ at Chunsu Harbor.

The area's cumulative changes were observed in 180 zones along the western coast of South Korea. The inner sea of Chunsu Harbor area accumulated an additional 200 ha of tidal flats per zone. A number of inner sea areas within Asan Harbor accumulated more than 50 ha of tidal flat area per zone. Bloc 1 within Nampo-Chunsu Harbor inner sea area also had an overall tidal flat increase. Most of the zones around Daeho-Asan Harbor area showed a significant increase in tidal flat area, especially towards the inner sea area of Asan Harbor.

The findings of this study show that remote sensing techniques can accommodate the special characteristic changes to tidal flat areas more effectively than traditional investigation methods. Also, this research suggests that taking the tidal water level into account when estimating tidal flat area changes will be vital in obtaining accurate change results with satellite images. As such, good findings of areal change can be obtained for difficultto-access tidal flat areas over a period of time when hydrographic charts and satellite images of a sufficient temporal extent are used. The results of this research provide areal change data that can be used 
to devise an environmental-friendly development plan for tidal flats.

\section{References}

Bartholdy J and Folving S 1986 Sediment classification and surface type mapping in the Danish Wadden sea by remote sensing; Netherlands J. Sea Research 20(4) 337-345.

Chen L C and Rau J Y 1998 Detection of shoreline change for tideland areas using multi-temporal satellite images; Int. J. Remote Sensing 19(17) 3383-3397.

David C M and Davenport I J 1996 Accurate and efficient determination of the shoreline in ERS-1 SAR images; IEEE Transactions on Geoscience and Remote Sensing 34(5) 1235-1253.

ERDAS Inc. 1991 ERDAS Field Guide. Atlanta, Georgia.

Jensen J R 1996 Introductory Digital Image Processing: A remote Sensing Perspective; Prentice-Hall, New York, USA.

Jeong J C 2002 Particulate distribution map of tidal flat using unsupervised classification of multi-temporary satellite data; Korean J. Remote Sensing 18(2) $71-79$.

Jo M H and Jo W R 1999 Micro-Landform Classification and topographic property of tidal flat in Julpo-Harbor using satellite image; Korean J. Remote Sensing 15(3) 217-225.

Kang M S, Park S W and Kim S M 2001 Estimating the variations of tidal flat areas after the seawall construction from topographic maps, hydrographic charts, and satellite images; J. Korea Water Resources Association (KWRA) 34(6) 597-604.

KARICO (Korea Agricultural \& Rural Infrastructure Corporation) 1992 Report of the changes on the submarine physiography and marine products; Kyeonggi-do, Korea.

Kim S J, Bang R S and Kwon H J 2003 Estimation of areal change in Hwa-ong tidal flat due to sea dike construction project using multi-temporal Landsat TM images; J. Korean National Committee of Irrigation and Drainage 10(1) 64-72.

Lee K S and Kim T H 2004 Topographic relief mapping on inter-tidal mudflat in Kyongki Bay area using infrared bands of multi-temporal Landsat TM data; Korean J. Remote Sensing 20(3) 163-173.

Lillesand T M and Kiefer R W 1994 Remote sensing and image interpretation (New York: John Wiley and Sons Inc.)

Lin J C 1996 Coastal modification due to human influence in South-Western Taiwan; Quat. Sci. Rev. 15 895-900.
MOMAF (Ministry of Maritime Affairs and Fisheries) 2002 Marine policy, RED trends; Kyeonggi-do, Korea, 28 pp.

Odum P O 1989 Ecology and out endangered life-support systems; Massachusetts, Sinauer.

Park S W 1988 Study on the predictions of the sea surface and the sedimentary layers in the Saemangeum Area (III); MAF, KARICO, Kyeonggi-do, Korea.

RIALS (Research Institute for Agriculture and Life Sciences) 2001 Study on the formation of tidal flats after Seawall Construction; Seoul National University, Seoul, Korea.

Rogan J and Chen D 2004 Remote sensing technology for mapping and monitoring land-cover and land-use change; Progress in Planning 61(4) 301-325.

Ryu J H et al 2000 Intertidal DEM generation using waterline extracted from remotely sensed data; Korean J. Remote Sensing 16(3) 221-223.

Ryu J H, Won J S and Min K D 2002 Waterline extraction from Landsat TM data in a tidal flat: A case study in Gomso Bay; Korea Remote Sensing of Environment $\mathbf{8 3}$ 442-456.

Ryu J H et al 2004 A critical grain size for Landsat ETM+ investigations into intertidal sediments: A case study of the Gomso tidal flats, Korea; Estuarine Coast. Shelf Sci. $60491-502$.

Sanjeevi S 1996 Morphology of dunes of the Coromandel coast of Tamil Nadu: A satellite data based approach for coastal landuse planning; Landscape and Urban Planning 34 189-195.

Steele J H 1995 An algorithm for the detection of the whitetide (Mucilage) phenomenon in the Adriatic Sea using AVHRR data; Remote Sens. Environ. 45 29-42.

Teillet P M, Fedosejevs G, Thome K J and Barker J L 2007 Impacts of spectral band difference effects on radiometric cross-calibration between satellite sensors in the solarreflective spectral domain; Remote Sensing of Environment (in Press, corrected proof available online 2 May 2007).

Wagle B G and Hashimi N H 1990 Coastal geomorphology of Mahe Island, Seychelles; Int. J. Remote Sensing 11(2) 281-287.

Weinstein M P and Weishar L L 2002 Beneficial use of dredged material to enhance the restoration trajectories of formerly diked lands; Ecological Engineering 19 187-201.

Weinstein M P et al 2000 Restoration principles emerging from one of the world's largest tidal marsh restoration projects; Wetlands Ecol. Manage 7L 1-21.

Won J S and Kim S W 2003 ERS SAR interferometry for tidal flat DEM; Proc. of FRINGE 2003 Workshop, Frascati, Italy.

Zhao B et al 2004 An ecosystem service value assessment of land-use change on Chongming Island, China; Land Use Policy 21 139-148. 